The online version of this article is published within an Open Access environment subject to the conditions of the Creative Commons Attribution-NonCommercial-ShareAlike licence < http:// creativecommons.org/licenses/by-nc-sa/2.5/ $>$. The written permission of Cambridge University Press must be obtained for commercial re-use.

doi: $10.1017 /$ So $144686 X_{12000827}$

\title{
Rural dementia carers: formal and informal sources of support
}

\author{
PETER ORPIN*, CHRISTINE STIRLING $\dagger$, \\ SHARON HETHERINGTON* and ANDREW ROBINSON $\dagger$
}

\begin{abstract}
Primary carers provide much of the day-to-day care for community-dwelling people living with dementia (PWD). Maintaining that contribution will require a more indepth understanding of the primary carer role and the support needs that flow from that role. This study explored patterns of formal and informal support utilisation by people caring for a PWD in a rural-regional context. In-depth semi-structured interviews were conducted with 18 rural primary carers of a PWD and thematically analysed. Participant primary carers' almost total commitment to, and absorption in their role and their assumption of ultimate responsibility for the PWD's wellbeing meant that external social context, such as rurality, became less relevant. Carer networks effectively contracted to those key individuals who were central to supporting them in their caring task. External sources of support were tightly managed with strong boundaries around the provision of direct care to the PWD largely excluding all but professional providers. Primary carers are generally categorised along with other family and friends as informal care. However, in assuming primary responsible for the care and wellbeing for the PWD they effectively become the key care provider, suggesting that it would be productive in both research and practice to treat primary carers as key members of a care partnership alongside professional carers, rather than as adjuncts to formal care and/or another client.
\end{abstract}

$\boldsymbol{K E Y} \boldsymbol{W O R D S}$ - dementia, primary carer, rural, support services.

\section{Background}

Ageing populations and lengthening lifespans (United Nations 2010) mean that dementia is a large and growing global problem with an estimated

* University Department of Rural Health, University of Tasmania, Hobart, Tasmania, Australia.

$\dagger$ Wicking Dementia and Research Education Centre, Menzies Research Institute, Hobart, Tasmania, Australia. 
24.3 million cases world-wide in 2005 projected to increase to 81.1 million by 2040 (Ferri et al. 2006). Despite advances in drug-based therapies to control symptoms and lengthen the disease trajectory, the management of dementia still largely consists of custodial care throughout a prolonged trajectory of decline. Outside of residential aged or specialist dementia care facilities, the vast majority of this care is delivered in the home by unpaid non-professionals; what is generally termed 'informal care' (Family Caregiver Alliance 2008; Nolan, Keady and Grant 1995; Nordberg et al. 2005; Simon 2001; Spector and Tampi 2005; Tester 1999; Wimo et al. 2011).

While the term informal care is generally taken to encompass all unpaid home-based care provided by 'close' family members and/or friends (Nordberg 2007), the majority of that care is provided by one emotionally and spatially proximal individual, the primary carer, most often either elderly spouses (McGarry and Arthur 2001; McGee et al. 2008) or children of the person with dementia (PWD) (Australian Institute of Health \& Welfare 2007a; Nolan, Keady and Grant 1995). Although the role is still poorly defined and often unrecognised and unacknowledged even by carers themselves (Jarvis and Worth 2005), primary carers are vital in maintaining a workable dementia care system (Etters, Goodall and Harrison 2008). Their contribution is central to all aspects of the wellbeing of the PWD (Yap et al. 2006), but especially in supporting them to remain in their homes and communities and out of residential care (Access Economics Pty Limited 2009; Brodaty et al. 2005; Nordberg 2007; Toseland et al. 2002).

There is considerable attention being paid to the support needs of primary carers in recognition not only of the importance of their contribution but the 'enormous amount and complexity of care that is performed by informal caregivers' (Nordberg 2007: $3^{8}$ ) and the level of challenge the role presents (Balducci et al. 2008; Eagar et al. 2007). Being a primary carer has been associated with a wide range of threats to health and wellbeing (Eagar et al. 2007) with carers experiencing poorer health (Donelan, Falik and DesRoches 2001; Mannion 2008a, 2008b), higher rates of depression (Adams 2007; Spector and Tampi 2005), increased stress levels (Rahman 1999), financial penalties (Chambers, Ryan and Connor 2001; Ross et al. 2008; Schofield et al. 1997), social isolation and exclusion (Chambers, Ryan and Connor 2001; Clements 2004; Schneider et al. 1999; Tilvis, Jolkkonen and Strandberg 2000), and increased mortality (Schulz and Beach 1999). These associations have led to a focus on primary caring as an essentially affectively negative, stressful and burdensome experience, and a tendency to conceptualise carer need largely in terms of one-dimensional, decontextualised measures of carer 'burden' (Hodgson, Higginson and Jefferys 1998).

A range of indicators suggest the need for a much more multi-dimensional and contextualised understanding of the carer experience and their 
support needs. In particular, to recognise its psycho-social complexity (Cheung and Hocking 2004) in which positive and negative affect, negative impact and positive value, co-exist in parallel and with quite a surprising degree of independence, rather than as opposite ends of a single continuum (Balducci et al. 2008; McKee et al. 2003). The under-utilisation of many currently available services primarily aimed at addressing carer burden (Brodaty 2005; Bruce et al. 2002; Cascioli et al. 2008; Eagar et al. 2007; Robinson et al. 2009) and the patchy effectiveness of many of these (Cooke et al. 2001; Yap et al. 2006) suggest that they are to some extent 'missing the mark' in terms of understanding and meeting carer support needs (Stirling et al. 2010). Reviews of carer interventions suggest that the approaches that are most effective in supporting carer coping are those that take a more balanced, nuanced approach to understanding the carer experience than simply focusing on carer burden (Andren and Elmstahl 2008; Eagar et al. 2007; Sorensen, Pinquart and Duberstein 2002; Stoltz, Uden and Willman 2004; Yap et al. 2006). The primary caring role is deeply embedded within, and shaped by, social contexts and relationships: between the carer and PWD; the carer and the formal or professional care providers; and the carer and their networks of family, friends and community. This suggests that determining and meeting the needs of primary carers requires approaches that seek to understand carers in terms of all of these contexts and relationships rather than simply as decontextualised individuals (Nomura et al. 2007).

There is a small body of research exploring relationships between primary and professional or formal carers, predominantly from a critical perspective, although these relationships remain inadequately theorised (Lyons and Zarit 1999). Overall, this research reveals general, and major, dissatisfaction among primary care-givers concerning their relationship with formal care providers. Many carers feel themselves and their contribution to be unrecognised, even invisible (Cascioli et al. 2008; Jarvis and Worth 2005; Ross, Holliman and Dixon 2003; Simon 2001), especially to the extent that the health professionals' focus on the PWD acts to exclude carers: 'an absence of attentiveness to the situations of caregivers can mean their needs for care go unmet and their capacity to care is compromised' (Barnes and Brannelly 2008: 388). Carpentier (2008) points to the importance of professional providers taking the time to develop a personal relationship of respect and trust with primary carers, a point echoed by Cascioli (2008: 22): '[it] was human contact that the carers were looking for in services'.

We found limited research addressing the relationship between the primary carer and other informal care providers such as family, friends and community. A major reason for this gap is likely the widely accepted division of dementia care into formal (professional), residential and informal (Access Economics Pty Limited 2009), the last grouping the primary carer 
into the same category as anyone or everyone who provides any unpaid support with activities of daily living (Family Caregiver Alliance 2008; Simon 2001; Spector and Tampi 2005). Such a broad and blunt categorisation is likely to, firstly, discourage an examination of the particularities of the primary carer role as distinct from other forms of informal care, and, secondly, obscure what are likely to be major interaction and relationship complexities within informal care networks, involving as they do individuals with very different levels of attachment, involvement and responsibility in respect of caring for the PWD.

One area in which informal care relationships have received more attention is in the context of the care of PWD in rural communities. Rural populations, at least in developed countries, are generally older and ageing faster than urban and have poorer baseline health across the age range (Australian Institute of Health \& Welfare 2007 ; Keating and Phillips 2008; Rogers 2002). Most tellingly, rural populations have access to fewer and less specialised services than their urban counterparts including medical dementia specialists (Access Economics Pty Limited 2009; Alzheimer's Australia 2007; Cahill 2000; Goins and Krout 2006; Innes et al. 2005, 2006; National Rural Health Alliance 2010). A lack of access, coupled with powerful narratives - if not a lot of solid empirical evidence - around the close-knit and supportive nature of rural community (Goins and Krout 2006; Keating 2008), suggest that family, friends and community are likely to play a larger and more important role in supporting the rural, as against the urban, primary dementia carer. This situation is, in turn, likely to give rise to a different and perhaps more visible dynamic, both within informal care networks and between those networks and formal carers, than that found where formal dementia care is more readily available.

Studies looking at the rural dementia experience do show that there is generally a greater reliance on informal rather than formal support services (Blackstock et al. 20o6; Cascioli et al. 20o8; McCann, Ryan and McKenna 2005; Morgan et al. 2005; Tommis 2007; Wenger, Scott and Seddon 2002). The reasons for this are, however, not entirely clear, especially whether this reflects an increased utilisation of informal services to compensate for inadequate formal services or rural carers simply managing with an overall lower level of, predominantly informal, support. Rural populations are acknowledged to be reluctant seekers and users of professional services whether due to inappropriate service models, access difficulties, distrust, stoic self-reliance and/or fears of stigmatisation (Fuller et al. 2ooo; Goins and Krout 2006; Morgan et al. 2002; Wenger, Scott and Seddon 2002). A study of dementia in rural Scotland by Innes, Blackstock and co-workers (Blackstock et al. 2006; Innes et al. 2005) revealed a complex picture with carers tending to rely more on individual friends and family than either 'community' or 
formal support, at least in the early stages of the disease trajectory but moving more towards professional support as the disease progressed and issues of stigma came into play. Their small study raises a number of issues around the way in which formal and informal services work, or fail to work, together in a way that meets rural carer need.

Wagner and Niles-Yokum (2006) point out that for all the research on carers, there are still major gaps in our understanding of the informal/ formal nexus and the rural context presents an ideal laboratory for exploring that issue. The study reported here interviewed rural carers of a PWD to explore their experience in seeking and accessing support for their role.

\section{Methodology}

Semi-structured interviews were conducted during 2009 with a convenience sample of 18 carers of PWD living in rural communities in Tasmania, Australia. Interviews, conducted in carers' homes, lasted on average $6_{3}$ minutes (range $25^{-108}$ minutes) and utilised an open and flexible structure to explore questions around carers' formal professional and informal support experience throughout the disease trajectory. This research was designed as an exploratory lead-in to a planned wider study into rural context as a possible factor in shaping the dementia experience and was, therefore, resourced for a limited sample of 20 participants. Recruitment was discontinued at 18 participants when it was judged that we had reached a degree of data saturation, both in terms of new issues emerging from the data and the level of evidential support for the main argument of this paper, therefore not justifying the increasing difficulty and costs of recruitment. Initial approaches to participants were made through dementia support agencies, with those willing to be interviewed contacting the researchers either directly or through the organisation. The sample, although both selective (in terms of agency contact) and self-selected, did not present as atypical of the population profile as reported by experienced local service providers. There was limited systematic collection of contextual data (Table 1), however the interview process with its broad focus on all forms and sources of received support yielded a very rich picture of family and social context which subsequently informed the analysis. All but one of the carers and all of the PWD were living outside the State's four major regional urban centres.

The final sample (Table 1) contained a balance of male and female, spousal and children carers. Eight of the carers were children looking after a parent (average age 59, four male and four female) and ten were partners/ spouses (average age 71 , six male and four female). All but one of the carers 
190 Peter Orpin et al.

TA B L E 1. Profile of primary care-givers interviewed

\begin{tabular}{lccccc}
\hline Carer code & Relationship to PWD & Carer gender & Carer age & PWD gender & PWD age \\
\hline A & Daughter & Female & 63 & Female & 85 \\
B & Spouse & Male & 47 & Female & 63 \\
C & Daughter & Female & 63 & Female & 88 \\
D & Son & Male & 59 & Male & 88 \\
E & Spouse & Male & 83 & Female & 81 \\
F & Son & Male & 53 & Male & 89 \\
G & Son & Male & 55 & Male & 85 \\
H & Spouse & Female & 72 & Male & 79 \\
I & Spouse & Female & 76 & Male & 86 \\
J & Daughter & Female & 68 & Female & 89 \\
K & Daughter & Female & 55 & Female & 90 \\
L & Son & Male & 54 & Male & 79 \\
M & Partner & Male & 58 & Female & 62 \\
N & Spouse & Female & 80 & Male & 84 \\
O & Spouse & Male & 63 & Female & 53 \\
P & Spouse & Male & 75 & Female & 68 \\
Q & Spouse & Female & 78 & Male & 78 \\
R & Spouse & Male & 75 & Female & 87 \\
\hline
\end{tabular}

Note: PWD: person with dementia.

was co-habiting with the PWD. The average age of the ten male and eight female PWD was 8 o years. Most had quite advanced dementia although they varied widely in the behavioural expression of the condition from relative passivity to highly challenging.

The interviews were audio recorded, transcribed verbatim and analysed within NVivo 8@ using a multi-stage iterative thematic analysis approach. The main emphasis in this research and analysis was to explore the lived experience of caring, in general, and patterns of formal and informal supports usage, in particular.

\section{Findings}

\section{The rural context}

The state of Tasmania is highly rural with 73 per cent of the population living outside of a major urban centre (Australian Bureau of Statistics 2010), however, it can be described as 'compactly' so. Although all but one participant lived in non-urban settings, none lived more than an hour's travel from a major regional centre and there were few aspects of their caring experience that might be attributed specifically to living rurally, especially in the absence of comparative urban data. Participants reported very limited access to specialist dementia physicians but none appeared to see this as a 
significant support gap, largely because most of their major concerns revolved around practical issues of day-to-day management, which were being well met by professional in-home care providers. There were widespread concerns about the level of expertise and support available from local general practitioners (GPs), particularly around getting a definitive diagnosis, however, there is nothing in the data to suggest that this reflected a rural rather than a wider general practice issue. These rural carers did, however, have limited GP alternatives compared to an urban context. There were a small number of references in the data to specific rural social and environmental characteristics but these were both positive and negative, although the latter came mainly from carers who were dealing with very challenging PWD behavioural issues, coping poorly and more generally dissatisfied: 'And I am so unlucky ... To be living in an area where people don't want to know each other' ${ }^{1}$ (Carer B). Most commonly, comments related to knowing and being known which most carers appreciated, but that at times did have a downside:

Oh, yeah, everybody knows him. That's why - it's a pretty safe area because even if he goes walkabout, I reckon go per cent know him, by sight. (Carer F)

Interviewer: How have the community reacted to what's happened with your dad?

Carer G: (Ironic laughter) Initially, you know it's, 'How's your dad going?' and stuff ... but... it's a country town which I think that just accentuates it but I've found that dementia's a bit like death; people don't want to talk about it... some people it makes more uncomfortable.

Overall, there was limited data specifically addressing the strengths, or weaknesses, of rural 'community' and rural informal support structures, despite interviewer questioning around the issue. Participants appeared simply too focused on the narrow and intense world of primary caring to devote attention to contexts outside that world.

\section{The primary carer role}

The findings suggest that understanding the patterns of service utilisation among primary carers in this study requires an awareness and acknowledgement of the emotionally dense, all-consuming and intensely private nature of the primary caring experience and responsibility. In particular, the manner in which this leads to an inward focus and the formation of strong social boundaries around the carer-PWD dyad. There is evidence of careful gatekeeping by carers in terms of who, among potential support providers, is admitted to this world, and how far they penetrate. In particular, carers were 


\section{Peter Orpin et al.}

highly reluctant to entrust any of their assumed responsibility as primary carer to others and then only to a select number of trusted, almost always professional, providers.

At one level, each carer's story and experience was unique; shaped by a complex mix of factors including PWD behaviours, their own coping skills and styles, the nature of the pre-existing relationship and the degree of match between support and need. While all carers were clearly finding the experience challenging, they varied widely in terms of how well they were coping. Carer A, a daughter caring for her mother, described her experience thus: 'It's just when you're swamped, you're drowning, you can't, you can't, you barely get your nose out of water and there's another wave.' Carer D, a son caring for his father, was much more sanguine: 'I don't know. At the moment it's going all right and if it's going all right, it's going all right' and Carer I was able to actually find some fun amongst the challenges of caring for her husband: 'But it's no good being cross ... So we have a lot of fun. We play games really.'

Regardless of the nature of individual experience and the diversity of factors shaping this experience, the most striking feature of virtually all the carer stories was the all-encompassing social and emotional intensity of the caring experience, most clearly shown in the level of role investment and commitment. For almost all of the carers interviewed, the carer role and relationship were all-consuming and marked by a very willing and full commitment to the care and welfare of the PWD. Most prominent in this was a sense of responsibility. That is, in terms of the care, comfort and wellbeing of the PWD 'the buck stopped with them', a commitment that took precedence over all other commitments in their life including to their own comfort and wellbeing. Most had, in this process, relinquished much that made up their pre-care life structure of work, family, friends and outside interests:

Carer C: $\quad$. . you become sort of, what would you say, your world becomes smaller, you tend to just - I often have a job to think past Mum and her needs and how I feel ... I do find myself perhaps cutting myself off a little bit from friends and other people and becoming less sociable...

Interviewer: (Addressing carer's husband) And from you? Carer C: Oh, yes.

While the interviews did not seek to explore meaning and identity directly, it is clear from the data that much that made the carers' pre-caring frameworks of meaning, identity and future view had also been transformed. Only a small number sought to hold on to some element of an independent life and some sense of a post-caring future by continuing part-time work or maintaining 
the occasional valued social or recreational engagements, but reported this to be a struggle:

Well yeah like there'd be an issue of like just complete change in your identity and everything because you're not working, you're not part of that sort of outside [world]... (Carer K)

I have been getting to Bridge which I quite enjoy. I'll never make a great Bridge player but ... it is a really good game to play and I thought will I go tomorrow? I need to look up all my notes, don't feel like it, and a friend rang and she said 'Just come', and I thought, yeah I think she's right. I think I've just got to do that, so that's what I'll do tomorrow. (Carer $\mathrm{H}$ )

For most, their 'needs' become defined entirely in terms of their caring role and the ability to sustain that role. Even self-care needs were framed in terms of sustaining their caring capacity:

I've just got to - my main thing is to try and make sure that I keep myself fit and healthy so that I can look after him when he needs it. And as we say we care for each other. (Carer I)

On the surface, this commitment and sense of responsibility could be read largely in terms of negatives: (constant) demand and (sometimes burdensome) obligation. However, when examined in the context of the wider narrative there is a deeper underpinning element of positive affect in terms of emotional rewards and satisfactions in giving and giving back:

Well, you see, I get up in the morning, I get M showered and everything, get dressed and have breakfast, do the washing, clean up and everything else you know. The place doesn't look too bad, does it? (Carer O)

The sense of being primarily responsible, however, both amplified the burden and shaped patterns of care seeking and utilisation. Carers were hyper-vigilant for the PWD's standard of care, wellbeing and comfort which led, firstly, to being very 'choosy' about to whom, and in what circumstances they would cede their responsibility and, secondly, to feelings of guilt whenever they did, regardless of their own need at the time:

So he's - and he's also very scared to be left on his own now. And, sort of, gets panicky even if he's left alone for a couple of minutes, he doesn't like being left alone at all ... So I normally have to wait till someone comes before I can have a shower. If it wasn't for the support that my brother and sister and I are giving him, he'd be dead, because he wouldn't be eating, he'd probably electrocute himself, he wouldn't be clean, he wouldn't be washing. And so, if you're the only one, yes, because, I mean, you've got to be with them, or try, and when they're not with you, you're thinking, 'What can I get done now before he gets back?' (Carer G)

When they did, reluctantly, cede their responsibility to others it was almost always, unlike Carer $\mathrm{G}$ above, to a trusted paid professional rather than family or friends. Despite this, they still worried: 'Well, .. [I] worry [when 


\section{Peter Orpin et al.}

away from PWD] because she might be, you know, just lonely and miserable and, of course, she doesn't do much' (Carer E). Carers A and C were both married women looking after their mothers and both, but particularly Carer A whose mother has paranoia, were feeling under considerable strain yet were limited users of respite. Carer A recounted a series of experiences with in-home respite where carers had lacked the specific detailed understanding of her mother's (admittedly complex) requirements: 'I keep on saying to them it's no use you sending me someone unless they're specifically dementia trained.'

Carer C, on the other hand, had trusted day-outing respite but, despite considerable need, was reluctant to access available residential care because she knew it disrupted her mother's world. She recounted the difficulty of crossing the yard to her mother's unit to tell her of a respite arrangement:

The first time we found it really hard and I... I have to keep myself really busy or ... you know, 'I wonder how she's going?' ... This is her world right here. She doesn't want to go outside that little world, you know. Being here, her dog and us - that, that's it.... and ... I left it until only a couple of days before to tell her that she was going but you know, it took me days, once again. I'd go to say to her, what was going to happen and I couldn't ... Then I'd walk across the courtyard to tell her and then I'd come back. [I was feeling] just horrible, like she's going to be upset and you know, I can't bear it if she does and will I lose my temper if she reacts in this way that I don't want her to and, you know, how will I accept that...

Carers employed strict criteria in terms of who they would willingly cede their responsibility to. Substitute carers needed to be someone with whom they and the PWD had established a warm relationship and whose expertise, care and competence they trusted completely:

She's more, yes, $\mathrm{R}$ is more than home help. She's actually a companion.... And she always takes A out. She used to take her swimming out to the thing, but it's a bit cold so they just go out for lunch. And R is just marvellous with her. (Carer E)

This sense of ultimate responsibility led to a clear demarcation between the ways different forms of support were accessed and managed.

\section{Patterns of carer support}

There was a clear division evident in the data between the way support was sought and used for, on one hand, the utilitarian tasks of maintaining a household and the mundane activities of daily living (including some of the more utilitarian tasks of caring for the PWD) and, on the other, the taking of responsibility for the care and wellbeing of the PWD. The former involved a mixture of formal and informal care, the latter almost exclusively formal care. An expected third form of support, that for the carer as an individual in 
their own right, separate from the dyad and their caring role, was notable for its almost total absence in the data. With a small number of exceptions carers expressed no extant sense of their individual need outside the caring role and where they did those needs were placed on hold for some distant future time:

I don't look too much in the future other than [I], should - I suppose 'should' is not the word, 'when' is probably the word if we're facing things, [PWD] deteriorates ... I don't know, I mean I'm not even projecting myself up that far to know... (Carer $\mathrm{H})$

Apart from a small number of exceptions, mostly those finding it hardest to cope, carers reported general satisfaction with the amount of available formal and informal support for the tasks of sustaining day-to-day home life with the PWD. The major issue with professional providers of these forms of support was not the availability, range or quality of individual services, which were reported as at least adequate, but service fragmentation and the resulting 'confusion' of services faced by carers. Carers, particularly the older carers, confessed to being confused about the multiple professional carers appearing at their door; which organisations they represented and the service they were providing and sometimes even their names: 'I mean, I just open the door and say, "Come in". Very confusing. Very confusing" (Carer P). Flowing from this, many carers presented as lacking a sense of control and confidence in managing these supports in a manner that best suited their needs:

Because there's so many different ones you get a bit flustered when they come, and probably don't get as much out of it as we should. It's not anybody's fault because it's sort of anybody in the department's job. (Carer N)

Support from family was mentioned in most interviews with most carers identifying just one, or occasionally two, key family members - usually a child, occasionally a sibling - who provided them day-to-day practical and/or emotional support. Other family were sometimes mentioned specifically for their lack of support or involvement. Out of three children, Carer E has one daughter who supports him in caring for his wife:

$\mathrm{S}$ [his son] I think is frightened. He doesn't come near her [PWD] ... nevertheless he did come around [following prompting from his sister] ... Well he's uh, tends to make very light of it and uh, I don't think he wants - but we haven't seen him since. So, or even heard from them so uh, that must've been a one-off I think. They [with wife] must've decided they couldn't do anything for us.

Most interestingly, with two or three exceptions, no family members were in any substantive way involved in the direct care of and/or taking any responsibility for the PWD. When asked about this, participants tended to talk in terms of family 'being busy' or 'having their own lives to lead', 
a response that underlines the sense that carers felt that caring for the PWD was primarily their responsibility and were reluctant to burden family with that responsibility.

Support from friends and neighbours appeared to follow a similar pattern with one or two key individuals identified as providing instrumental support with day-to-day living. One case apart, however, none of these informal supporters appeared to have any direct involvement in the care and management of the PWD. A number of participants mentioned community but only in the sense that they felt their community would 'keep an eye out' for the PWD in the carer's absence:

Interviewer: So your community has been quite supportive?

Carer G: Oh, yeah, everyone knows everybody. Yes, it's not a bad community, actually, as they go. It would be strange to go back to the city now.

In respect of any support involving direct care of, or assuming responsibility for, the PWD, participants relied almost exclusively on professional or formal support. There would appear to be two major reasons for this, although one is more explicit than the other in the data. Most clearly, the priority for carers was to identify individuals who they could trust and they believed to have the experience and expertise to support them in their role and/or to assume care of the PWD with minimal compromise to the PWD's comfort and overall wellbeing in their absence.

Within the Australian context, the first and most logical source of professional support in managing the PWD is the GP. While satisfaction with individual GP's knowledge and support varied widely, there are only limited examples in the data of fully satisfactory and functional dementia management partnerships between carers and GPs and a greater number of stories that demonstrate the failure of that partnership; for example in areas of diagnosis, medical management and difficult decisions such as driving licence withdrawal:

So you'd walk away [from GP appointment] still thinking, 'Well, does she have a problem, or do I have a problem?', or, you know, they're not really acknowledging it, but underneath I think they knew, but they weren't talking about it... (Carer C)

... I think it's probably one of the hardest things ... when I-and again, I lay this squarely at the feet of the male doctor that Dad had at the time-approved his ... medical for his driver's licence. . . . Now, a few months later I had to take Dad's car away from him. Now he'd driven since he was 12 , and it was massive and that really hurt me, you know, I mean, he cried. It was really, really, difficult. (Carer L)

In contrast, a satisfactory partnership with a GP greatly eased the carer role. Carer $Q$, as primary carer for her husband despite her own poor health and 
cognitive problems, relied heavily on her GP for support in handling her husband's medication:

So I was telling A [GP]. He said, 'Bring one round and show me. Next time you get them' ... so I did that and ... he said, 'Look, you used to do them before, didn't you?' I said, 'Yes'. And he said, 'Well, do you think you could do them again?' and I said, 'Well, if you write it all down for me, I'll do it' so he did. He sat down and named everything he's got to take and what days he's got to - well, how many times a day and so on and it's as easy as winking. So I do it Sunday afternoon or Sunday evening, I sit down to do them up for the week.

In practice, almost all of the carers had singled out and developed a relationship with one professional, usually an in-home service provider who, regardless of their substantive role, became not only a trusted direct care provider to the PWD but a critical lifeline, anchor and connection point into the system:

And a phone call, or whatever, is all I need to, you know, and they say, 'If it's available, or something, we'll find it out for you.' (Carer F)

Well, one of the major, well the major person actually was M. She was very good to Mum and Dad when Dad was still alive, and when he died she was absolutely wonderful to my mother and to me. So I don't know what we would have done without her at the time. (Carer J)

Many other professional providers, from household cleaners to GPs, however technically competent and even caring, appeared to flow through the carers' personal space without fully engaging or connecting with the carer or the PWD.

Accessing respite constitutes a major handing over of responsibility for caring. Carers were, in the main, regular and satisfied users of short-term in-home respite services where the PWD could be left for short periods with a known (to both carer and the PWD) and trusted professional carer. They were, however, reluctant users of out-of-home respite which they saw as, or more often knew from experience to be, because of the disruption it caused, a threat to the comfort and emotional wellbeing of the PWD. Such 'respite' therefore provided little in the way of a true 'break' from the emotional and psychological demands of caring and effectively overlaid guilt on to existing stresses:

Well, we went away. The first time we found it really hard and I- everyone says don't worry, don't come and see her, don't call, don't do this. I have to keep myself really busy or, you know, you ... [think], 'I wonder how she's going?' But I didn't call, you see, I thought, well, it's only going to upset me if they say she's not happy, so I thought best not to know, what you don't know doesn't hurt you. And even though we came home I think the first time ... we couldn't even go up to see her because she would have thought, 'Well, I can go home. If [carer] is home, that's it, I don't have to be here'. (Carer C) 


\section{Peter Orpin et al.}

A second likely reason for the almost total reliance on formal sources for direct care and support appears in the data more in terms of omission and silence than direct evidence. Most carers clearly had access to identifiable sources of informal support, both family and friends, that appeared to meet the criteria for providing direct care and support to the PWD. That is, they were apparently willing, fully competent adults, known and trusted by the PWD and, in the case of non-kin, had a long-term pre-dementia relationship with the family. Carers explained the non-involvement of these individuals in direct care in terms of them 'having their own lives to lead'. However, even cases where close kin were identified as a constant and close support to the dyad, there appeared to be a clear exclusionary boundary beyond which they did not penetrate. There appeared to be an unstated process of 'gatekeeping' by the carer, either protecting, or excluding, non-professionals such as family and friends, from the burden, responsibility and/or reality of the full caring experience.

\section{Discussion}

This study was designed to explore the experience of being a primary carer for a PWD in a rural context, with particular emphasis on patterns of service usage. The combination of known limitations in access to a range of health and support services and strong narratives about the supportive nature of rural community, suggests that the rural context presents an ideal site for exploring the ways in which carers manage available informal and formal supports in order to meet their needs. The findings do provide a rich insight into the primary carer experience and reveal quite distinct patterns of service usage although, without comparative data, it cannot be argued that these experiences are peculiar to the rural context.

In fact, neither of the original rationales behind the choice of the rural setting for the study are particularly evident in these data. Overall, participants do not report any major concerns about the availability of, or their access to, formal support services, although a small number did express dissatisfaction with the appropriateness of some service models, especially respite services, and the knowledge and expertise of some service providers, particularly GPs. However, without larger-scale comparative data it is not possible to draw any conclusions from this about the overall adequacy of formal rural dementia services and supports, beyond these limited study areas. Also, these relatively high levels of satisfaction may be as much a reflection of low expectations as of adequacy of supply; reluctant help-seeking among rural cohorts is well recognised, particularly in relation to mental health issues (Brodaty et al. 2005; Fuller et al. 2000; 
Howse, Ebrahim and Gooberman-Hill 2004). There is an acknowledged short-fall in dementia specialist physicians in rural Australia (Access Economics Pty Limited 2009), however, none of the participants reported that a lack of access to such specialists was a particular issue in terms of performing their day-to-day role as primary carer. Deficiencies in rural GP dementia knowledge and management skills, especially in regard to diagnosis, have been reported elsewhere (Brodaty, Green and Koschera 2003; Bruce et al. 2002; Glasser 1993; Hansen et al. 2005, 2008; Mason et al. 2005). However, as with the issue of supply, a lack of comparative studies makes it difficult to determine to what extent this represents a peculiarly rural issue.

There is also little in the data to support, or refute, assumptions about the 'close and caring' nature of rural community. Carers generally reported their communities as supportive, at least up to the point that the PWD's behaviours become publicly confronting, and almost all appeared reasonably satisfied with the available support from family and friends. Tasmania can be described as compactly rural with a history of low (but increasing) population mobility and most reported at least one family member and/or close friend who lived close enough for convenient daily contact. However, for most, their world had contracted to the point where it was almost entirely defined by the dyadic relationship and caring task, and interactions with family and friends were largely confined to the small and select number of individuals who provided utilitarian and, to some extent, emotional support to the primary carer. Even for these individuals there were clear limits to their penetration of the dyadic relationship. Although narratives about the close-knit and caring nature of rural community are widely prevalent in the popular, and some cases academic, literature, it is difficult to find empirical support for this, especially in terms of direct urban-rural comparative studies.

Carers are revealed as being pragmatic and resourceful in accessing support from whatever sources they can in order to meet their needs. However, two themes emerge clearly which hold across the cases. The first concerns the manner in which the all-consuming socio-emotional intensity and assumed responsibility of the caring task shrinks and focuses the carers' social world. The second relates to the carer's construction and maintenance of a strong socio-emotional boundary at the point where support impinges on the intimate interpersonal space of the carer-PWD dyad, especially where that involves any transfer of direct care responsibility away from the primary carer. That boundary effectively excludes all but a small number of formal/ professional care providers. Taken together, these themes suggest that understanding carer need and help-seeking behaviour requires a deeper, more sophisticated and multi-dimensional understanding of the primary carer role and experience than provided by one-dimensional measures of carer burden. 
There is a large body of literature exploring hardship models of the carer as 'individual in need', expressed most clearly in measures of carer burden (Brouwer et al. 2006; Burns and Rabins 2000; Butler et al. 2005; Chenier 1997; Deeken et al. 2003; Eagar et al. 2007; Schneider et al. 1999; Yap et al. 20o6). However, as Marks ( 1998) pointed out 'it doesn't always hurt to care'. A more rounded picture of the primary caring experience as a psychosocially complex and co-existent mixture of challenges and satisfactions is emerging (Balducci et al. 2008; Cheung and Hocking 2004; McKee et al. 2003). This work highlights the importance of carers' meaning-making and psycho-social and emotional skills and knowledge resources in shaping the carer experience and ability to cope (Andren and Elmstahl 20o8; Cooper et al. 2008; Croog et al. 2006; De Vugt et al. 2004; Jarvis, Worth and Porter 2006; Rutherford-Kitson, Burton-Smith and Ball 2002; Yap et al. 2006). There is, however, still a dearth of research which treats the dyadic caring relationship, rather than the carer or PWD in isolation, as the unit of analysis. The data in this study suggest that the care experience, and therefore carer support needs, cannot be understood outside of the context and dynamic of that relationship. In particular, the manner in which the acceptance of the role of primary carer with its implications of ultimate responsibility for the PWD's comfort and wellbeing, colours, if not structures, all of the primary carer's social relationships including those with formal and informal support providers.

Most of the in-depth research into the carer experience and the relationship between primary and professional care providers is very 'topdown' and paternalistic in that it is primarily concerned with exploring the ways in which the formal providers can best 'care for' primary carers. If, as this study suggests, it is the primary carers rather than the professionals who are, in reality and practice, accepting and carrying primary and ultimate responsibility for the ongoing care, comfort and wellbeing of the PWD, they would appear to be not so much in need of care, as supportive partnership. That is, their priority is not finding professional providers who will take care of them - apart from where it will help them to sustain their caring role - but who will work with them to ensure the best care outcomes for the PWD. Current research suggests that many carers feel themselves and their contribution under-valued, unrecognised, even invisible (Cascioli et al. 2008; Jarvis and Worth 2005; Ross, Holliman and Dixon 2003; Simon 2001), especially when health professional focus is on the PWD: 'an absence of attentiveness to the situations of caregivers can mean their needs for care go unmet and their capacity to care is compromised' (Barnes and Brannelly 2008: 388, italics added). Both Carpentier (2008) and Cascioli et al. (2008) point to the importance of professional providers taking the time to develop a personal relationship of respect and trust with primary carers: 'They [carers] 
desired more visits from people with empathy, understanding and the ability to provide advice and assistance should it be needed' (Cascioli et al. 20o8: 22). Study participants overwhelmingly felt themselves ill-equipped for their assumed task and looked to trusted professionals for assistance in building their skills, knowledge, capacity and confidence. As Lund (2005) and others point out, the primary carer almost always comes to the carer role, with its technical/clinical, logistical and psycho-social challenges, unprepared:

... knowing how to provide care for a person with dementia is not an innate skill and is not acquired solely through a motivation to care, rather [it] is learned and acquired through guidance, experiences and support from knowledgeable care providers. (Kelley, Buckwalter and Maas 1999: 9)

While there are doubts over whether knowledge provision alone can improve carer outcomes (Eagar et al. 2007), approaches and supports that focus on equipping the primary carer as a key provider in need of proper training, rather than as an unskilled adjunct to formal care, appear the most promising (Brodaty, Green and Koschera 2003; Eagar et al. 2007; Sorensen, Pinquart and Duberstein 2002).

The finding that primary carers are not involving even the closest family and friends in the provision of direct care of the PWD - perhaps even actively excluding them - is likely also to be related to the emotionally dense and intensely private nature of the dyad, and the primary carer's sense of responsibility within that. In choosing to cede care and responsibility only to paid professionals, carers can have some confidence, firstly, that the substitute carer will have sufficient skills and knowledge to minimise any disruption to the PWD's care and comfort and, secondly, that they are transferring their responsibility to someone who, unlike family and friends, is paid to accept that responsibility. Although it is difficult to pinpoint direct evidence for this in the data, it is also likely that carers are seeking to protect both the PWD from having their pre-dementia identity discredited, and family and friends from the reality of the condition.

\section{Limitations}

This is a small study in a quite specific policy and practice environment which restricts its generalisation beyond that context. In particular, without comparative urban data it is not possible, nor was the study designed to be able to, attribute the findings specifically to the rurality of the context. The lack of support across the sample for a thesis that rural context was a major influence in shaping the experience of caring for a PWD was one factor in the decision to discontinue recruitment at 18 participants and to not proceed in the short term with a wider study. A high level of data saturation 
in terms of support for the major findings reported here suggests that the study provides important insights into primary carer roles and needs and that these warrant attention and testing across other spatial and social contexts.

\section{Conclusion}

This study sought to utilise a rural context to explore patterns of formal and informal support accessed by primary carers of a PWD. The study produced limited evidence that the rural context was a major factor in shaping these patterns. Rather, the findings suggest participants' support usage was shaped less by external contexts than by the fundamental nature of the primary caring experience, in particular the emotionally intense, clearly bounded and inwardly focused nature of the caring relationship and the manner in which carers perceived and sought to fulfil their assumed role as the person primarily and ultimately responsible for the care and wellbeing of the PWD. While in research and practice primary carers are generally categorised along with other family, friends and community as 'informal' care, the findings suggest that the role assumed and care delivered by study participants had very little in common with the roles played by other nonprofessionals involved with the carer-PWD dyad. In terms of the level of involvement, commitment, assumption of responsibility and even expertise in the sense of a specialised knowledge and understanding of the care and management needs of the individual PWD - the care provided by these primary carers was fundamentally different from, and went well beyond, that provided by anyone else in the care team, formal or informal. A failure to acknowledge and recognise the true nature of the primary caring role and contribution can, and most likely has, led to primary carers being seen as mere adjuncts to professional care and/or as another client in need of care rather than as essential care partners. As such, they were not so much in need of release or relief from their role as the support to allow them to manage the task they have undertaken through the building of appropriate knowledge, skills, capacity and support structures.

It is difficult, without comparative data, to speculate on the degree to which these findings are generalisable to other primary care-giver roles. In many respects, the level and nature of the challenge faced by dementia carers is likely to be replicated in other primary caring situations. It therefore could be argued that the need to be acknowledged and treated as full care partners by professional providers is likely to be shared by all those assuming primary responsibility for the care of another. However, dementia, because of its later life onset and challenging manifestation can be seen to be at least 
particular, if perhaps not unique (e.g. stroke, acquired brain injury) in two respects. Firstly, in its potential to disrupt and discredit identities, personas, reputations and relationships built up over a lifetime. This can lead to carers feeling a particular need to maintain social boundaries in order to protect both the PWD and family and friends from these impacts. Secondly, the gradual loss of the PWD's ability to function as the responsible and autonomous adult that they had been most of their lives can lead to legal, moral and social ambiguities around issues of control, authority and responsibility. These fall almost entirely to the primary carers to negotiate as they seek to discharge their assumed responsibilities.

\section{Acknowledgements}

This study was approved by the Human Research Ethics Committee (Tasmania), a partnership organisation involving the University of Tasmania and the State Government. The study authors wish to acknowledge the Faculty of Health Science, University of Tasmania for the provision of seed funding for this research.

\section{NOTE}

1 The following conventions have been followed in quotations: '...' indicates text omitted for reasons of brevity where the omission of such text does not materially alter the sense or meaning of the quote. '-' indicates a break or disjunction in the flow of speech generally related to the speaker's efforts to reorder their thoughts and/or the expression of those thoughts.

\section{References}

Access Economics Pty Limited 2009. Making Choices. Future Dementia Care: Projections, Problems and Preferences. Alzheimer's Australia, Hawker, Australia.

Adams, K. B. 2007. Specific effects of caring for a spouse with dementia: differences in depressive symptoms between caregiver and non-caregiver spouses. International Psychogeriatrics, 20, 3, 508-20.

Alzheimer's Australia 2007. Support Needs of People Living with Dementia in Rural and Remote Australia. Alzheimer's Australia, Hawker, Australia.

Andren, S. and Elmstahl, S. 2008. The relationship between caregiver burden, caregivers' perceived health and their sense of coherence in caring for elders with dementia. Journal of Clinical Nursing, 1 7, 6, 790-9.

Australian Bureau of Statistics 2010. National Regional Profile: Tasmania. Commonwealth of Australia, Canberra.

Australian Institute of Health \& Welfare 2007a. Dementia in Australia National Data Analysis and Development. Australian Institute of Health \& Welfare, Canberra.

Australian Institute of Health \& Welfare $2007 b$. Older Australia at a Glance. Fourth edition, Cat. No. AGE 52, Australian Institute of Health and Welfare, Canberra.

Balducci, C., Mnich, E., McKee, K. J., Lamura, G., Beckmann, A., Krevers, B., Beata, W. Z., Nolan, M., Prouskas, C., Bien, B. and Oberg, B. 2008. Negative impact and 


\section{Peter Orpin et al.}

positive value in caregiving: validation of the COPE index in a six-country sample of carers. The Gerontologist, 48, 3, 276-86.

Barnes, M. and Brannelly, T. 2008. Achieving care and social justice for people with dementia. Nursing Ethics, 15, 3, 384-95.

Blackstock, K. L., Innes, A., Cox, S., Smith, A. and Mason, A. 2006. Living with dementia in rural and remote Scotland: diverse experiences of people with dementia and their carers. Journal of Rural Studies, 22, 2, 161-76.

Brodaty, H. 2005. Familes of people with dementia. In Sartorius, N., Maj, M. and Okasha, A. (eds), Families and Mental Disorder: From Burden to Empowerment. John Wiley and Sons, New York, $25^{-} 54$.

Brodaty, H., Green, A. and Koschera, A. 2003. Meta-analysis of psychosocial interventions for caregivers of people with dementia. Journal of the American Geriatrics Society, 51, 5, 657-64.

Brodaty, H., Thomson, C., Thompson, C. and Fine, M. 2005. Why caregivers of people with dementia and memory loss don't use services. International Journal of Geriatric Psychiatry, 2o, 6, 537-46.

Brouwer, W., van Exel, N., van Gorp, B. and Redekop, W. 20o6. The CarerQol instrument: a new instrument to measure care-related quality of life of informal caregivers for use in economic evaluations. Quality of Life Research, $\mathbf{1 5}$, $6,1005^{-21}$.

Bruce, D. G., Paley, G. A., Underwood, P.J., Roberts, D. and Steed, D. 2002. Communication problems between dementia carers and general practitioners: effects on access to community support services. Medical Journal of Australia, 177, 4, $186-8$.

Burns, A. and Rabins, P. 20oo. Carer burden in dementia. International Journal of Geriatric Psychiatry, 15, supplement 1, S9-13.

Butler, S. S., Turner, W., Kaye, L. W., Ruffin, L. and Downey, R. 2005. Depression and caregiver burden among rural elderly caregivers. Journal of Gerontological Social Work, 46, 1, 47-63.

Cahill, S. 200o. Elderly husbands caring at home for wives diagnosed with Alzheimer's disease: are male caregivers really different? Australian Journal of Social Issues, 35, 1, 53-72.

Carpentier, N. 2008. Social care interface in early-stage dementia: practitioners' perspective on the links between formal and informal networks. Journal of Aging and Health, 2o, 6, 710-38.

Cascioli, T. R., Al-Madfai, H., Oborne, P. and Phelps, S. 20o8. An evaluation of the needs and service usage of family carers of people with dementia. Quality in Ageing, 9, 2, $18-27$.

Chambers, M., Ryan, A. A. and Connor, S. L. 2001. Exploring the emotional support needs and coping strategies of family carers. Journal of Psychiatric and Mental Health Nursing, 8, 2, 99-106.

Chenier, M. C. 1997. Review and analysis of caregiver burden and nursing home placement: the multiple problems and variables affecting the caregiving relationships require multiple approaches and interventions. Geriatric Nursing, $18,3,121-6$.

Cheung, J. and Hocking, P. 2004. Caring as worrying: the experience of spousal carers. Journal of Advanced Nursing, 47, 5, 475-82.

Clements, L. 2004. Carers - the sympathy and services stereotype. British Journal of Learning Disabilities, 32, 1, 6-8.

Cooke, D. D., McNally, L., Mulligan, K. T., Harrison, M. J. G. and Newman, S. P. 2001. Psychosocial interventions for caregivers of people with dementia: a systematic review. Aging $\mathcal{E}^{2}$ Mental Health, 5, 2, 120-35. 
Cooper, C., Katona, C., Orrell, M. and Livingston, G. 2008. Coping strategies, anxiety and depression in caregivers of people with Alzheimer's disease. International Journal of Geriatric Psychiatry, 23, 9, 929-36.

Croog, S. H., Burleson, J. A., Sudilovsky, A. and Baume, R. M. 20o6. Spouse caregivers of Alzheimer patients: problem responses to caregiver burden. Aging $\mathcal{E}$ Mental Health, 10, 2, 87-100.

De Vugt, M. E., Stevens, F., Aalten, P., Lousberg, R., Jaspers, N., Winkens, I., Jolles, J. and Verhey, F. R. J. 2004. Do caregiver management strategies influence patient behaviour in dementia? International Journal of Geriatric Psychiatry, 19, 1, 85-92.

Deeken, J. F., Taylor, K. L., Mangan, P., Yabroff, K. R. and Ingham, J. M. 2003. Care for the caregivers: a review of self-report instruments developed to measure the burden, needs, and quality of life of informal caregivers. Journal of Pain and Symptom Management, 26, 4, 922-53.

Donelan, K., Falik, M. and DesRoches, C. M. 2001. Caregiving: challenges and implications for women's health. Women's Health Issues, 1 1, 3, 185-200.

Eagar, K., Owen, A., Williams, K., Westera, A., Marosszeky, N., England, R. and Morris, D. 2007. Effective Caring: A Synthesis of the International Evidence on Carer Needs and Interventions. Centre for Health Service Development, University of Wollongong, Wollongong, Australia.

Etters, L., Goodall, D. and Harrison, B. 2008. Caregiver burden among dementia patient caregivers: a review of the literature. Journal of the American Academy of Nurse Practice, 2o, 8, 423-8.

Family Caregiver Alliance 2008. Selected Caregiver Statistics. Available online at www. caregiver.org/caregiver/jsp/content_node.jsp?nodeid=439. [Accessed October 2010]

Ferri, C. P., Prince, M., Brayne, C., Brodaty, H., Fratiglioni, L., Ganguli, M., Hall, K., Hasegawa, K., Hendrie, H. and Huang, Y. 2006. Global prevalence of dementia: a Delphi consensus study. The Lancet, 366, 9503, $2112-7$.

Fuller, J., Edwards, J., Procter, N. and Moss, J. 20oo. How definition of mental health problems can influence help seeking in rural and remote communities. Australian Journal of Rural Health, 8, 3, 148-53.

Glasser, M. 1993. Alzheimer's disease and dementing disorders: practices and experiences of rural physicians. American Journal of Alzheimer's Disease and Other Dementias, 8, 4, 28-35.

Goins, R. T. and Krout, J. A. (eds) 20o6. Service Delivery to Rural Older Adults: Research Policy and Practice. Springer Publishing Company, New York.

Hansen, E. C., Hughes, C., Routley, G. and Robinson, A. L. 20o8. General practitioners' experiences and understandings of diagnosing dementia: factors impacting on early diagnosis. Social Science $\mathcal{E}$ Medicine, 67, $11,1776-83$.

Hansen, E., Robinson, A., Mudge, P. and Crack, G. 2005. Barriers to the provision of care for people with dementia and their carers in a rural community. Australian Journal of Primary Health, 11, 1, 72-9.

Hodgson, C., Higginson, I. and Jefferys, P. 1998. The Carer Checklist: An Outcome Measure for People with Dementia and Their Carers. The Mental Health Foundation, London.

Howse, K., Ebrahim, S. and Gooberman-Hill, R. 2004. Help-avoidance: why older people do not always seek help. Reviews in Clinical Gerontology, 14, 1, 63-70.

Innes, A., Blackstock, K., Mason, A., Smith, A. and Cox, S. 2005. Dementia care provision in rural Scotland: service users' and carers' experiences. Health $\mathcal{E}$ Social Care in the Community, 13, 4, 354-65.

Innes, A., Cox, S., Smith, A. and Mason, A. 2006. Service provision for people with dementia in rural Scotland: difficulties and innovations. Dementia, 5, 2, 249-70. 
Jarvis, A. and Worth, A. 2005. The development of a screening tool to identify carers in a general practice by a large-scale mailed survey: the experience in one Scottish general practice. Journal of Clinical Nursing, 14, 3, 363-72.

Jarvis, A., Worth, A. and Porter, M. 20o6. The experience of caring for someone over 75 years of age: results from a Scottish General Practice population. Journal of Clinical Nursing, 15, $11,145^{\circ}-9$.

Keating, N. (ed.) 2008. Rural Ageing: A Good Place to Grow Old? The Policy Presss, Bristol, UK.

Keating, N. and Phillips, J. 2008. A critical human ecology perspective on rural ageing. In Keating, N. (ed.), Rural Ageing: A Good Place to Grow Old? The Policy Presss, Bristol, UK, $1-10$.

Kelley, L. S., Buckwalter, K. C. and Maas, M. L. 1999. Access to health care resources for family caregivers of elderly persons with dementia. Nursing Outlook, 47, 1, 8-14.

Lund, M. 2005. Caregiver, take care. Geriatric Nursing, 26, 3, 152-3.

Lyons, K. S. and Zarit, S. H. 1999. Formal and informal support: the great divide. International Journal of Geriatric Psychiatry, 14, 3, 183-92.

Mannion, E. 2008a. Alzheimer's disease: the psychological and physical effects of the caregiver's role. Part 1. Nursing Older People, 2o, 4, 27-32.

Mannion, E. 2008b. Alzheimer's disease: the psychological and physical effects of the caregiver's role. Part 2. Nursing Older People, 2o, 4, 33-8.

Marks, N. F. 1998. Does it hurt to care? Caregiving, work-family conflict, and midlife well-being. Journal of Marriage and the Family, 6o, 4, 95 1-66.

Mason, A., Blackstock, K., Cox, S., Innes, A. and Smith, A. 2005. Dementia services in rural areas: nursing implications. Nursing Older People, 17, 9, 20-3.

McCann, S., Ryan, A.A. and McKenna, H. 2005. The challenges associated with providing community care for people with complex needs in rural areas: a qualitative investigation. Health $\mathcal{E}$ Social Care in the Community, 13, 5, $462-9$.

McGarry, J. and Arthur, A. 2001. Informal caring in late life: a qualitative study of the experiences of older carers. Journal of Advanced Nursing, 33, 2, 182-9.

McGee, H. M., Molloy, G., O'Hanlon, A., Layte, R. and Hickey, A. 2008. Older people -recipients but also providers of informal care: an analysis among community samples in the Republic of Ireland and Northern Ireland. Health E Social Care in the Community, 16, 5, 548-53.

McKee, K. J., Philp, I., Lamura, G., Prouskas, C., Oberg, B., Krevers, B., Spazzafumo, L., Bien, B., Parker, C. and Nolan, M. R. 2003. The COPE index-a first stage assessment of negative impact, positive value and quality of support of caregiving in informal carers of older people. Aging and Mental Health, 7, 1, 39-52.

Morgan, D. G., Semchuk, K. M., Stewart, N.J. and D'Arcy, C. 2002. Rural families caring for a relative with dementia: barriers to use of formal services. Social Science Ẽ Medicine, 55, 7, $1129-42$.

Morgan, D. G., Stewart, N. J., Crossley, M., D’Arcy, C., Biem, J., Kirk, A. and Forbes, D. 2005. Dementia care in rural and remote areas: the first year of a CIHR new emerging team. Canadian Journal of Nursing Research, 37, 1, 177-82.

National Rural Health Alliance 2010. Measuring the Metropolitan-Rural Inequity. National Rural Health Alliance, Policy Document. Available online at http://nrha. ruralhealth.org.au/ftp/NRHA-measuring-the-inequity.pdf. [Accessed April 2011 ]

Nolan, M., Keady, J. and Grant, G. 1995. Developing a typology of family care: implications for nurses and other service providers. Journal of Advanced Nursing, $\mathbf{2 1}$, $2,25^{6-65}$.

Nomura, M., Makimoto, K., Kato, M., Shiba, T., Matsuura, C., Shigenobu, K., Ishikawa, T., Matsumoto, N. and Ikeda, M. 2007. Empowering the elderly with early 
dementia and family caregivers: a participatory action research study. International Journal of Nursing Studies, 46, 4, 431-41.

Nordberg, G. 2007. Formal and Informal Care in an Urban and a RuralElderly Population: Who? When? What? Aging Research Center, Karolinska Institutet, Stockholm, Sweden.

Nordberg, G., Strauss, E.v., Kåreholt, I., Johansson, L. and Wimo, A. 2005. The amount of informal and formal care among non-demented and demented elderly persons - results from a Swedish population-based study. International Journal of Geriatric Psychiatry, 2o, 9, 862-71.

Rahman, N. 1999. Understanding conflict: perception of female caregivers. Australian Journal on Ageing, 18, 140-4.

Robinson, A., Elder, J., Emden, C., Lea, E., Turner, P. and Vickers, J. 2009. Information pathways into dementia care services: family carers have their say. Dementia, 8, 1, 17-37.

Rogers, C. C. 2002. The older population in 21 st century rural America. Rural America, 17, 3, 2-10.

Ross, A., Lloyd, J., Weinhardt, M. and Chershire, H. 2008. Living and Caring? An Investigation of the Experiences of Older Carers. National Centre for Social Research on behalf of the International Longevity Centre - UK (ILC-UK), London, UK.

Ross, L., Holliman, D. and Dixon, D. R. 2003. Resiliency in family caregivers: implications for social work practice. Journal of Gerontological Social Work, 4o, 3, $81-96$.

Rutherford-Kitson, A., Burton-Smith, R. and Ball, P. 2002. Caring for a partner: the impact of resources on caregivers' health in rural and urban Tasmania. Australian Journal of Psychology, 54, 2, $110-35$.

Schneider, J., Murray, J., Banerjee, S. and Mann, A. 1999. EUROCARE: a crossnational study of co-resident spouse carers for people with Alzheimer's disease: I - Factors associated with carer burden. International Journal of Geriatric Psychiatry, $\mathbf{1 4}, 8,65^{1-61 .}$

Schofield, H. L., Herrman, H. E., Bloch, S., Howe, A. and Singh, B. 1997. A profile of Australian family caregivers: diversity of roles and circumstances. Australian and New Zealand Journal of Public Health, 21, 1, 59-66.

Schulz, R. and Beach, S. R. 1999. Caregiving as a risk factor for mortality: the caregiver health effects study. Journal of the American Medical Association, 282, 23, $2215^{-9}$.

Simon, C. 2001 . Informal carers and the primary care team. British Journal of General Practice, 51, 472, 920-3.

Sorensen, S., Pinquart, M. and Duberstein, P. 2002. How effective are interventions with caregivers? An updated meta-analysis. Gerontologist, 42, 3, 356-72.

Spector, J. and Tampi, R. 2005. Caregiver depression. Annals of Long Term Care, 13, 4,34 .

Stirling, C., Andrews, S., Croft, T., Vickers, J., Turner, P. and Robinson, A. 2010. Measuring dementia carers' unmet need for services-an exploratory mixed method study. BMC Health Services Research, 10, 122 . Available online at http://www. biomedcentral.com/1472-6963/10/122. [Accessed October 2011].

Stoltz, P., Uden, G. and Willman, A. 2004. Support for family carers who care for an elderly person at home - a systematic literature review. Scandanavian Journal of Caring Science, 18, 2, 111 1-9.

Tester, S. 1999. Commentary on: useful services for families: research findings and directions. International Journal of Geriatric Psychiatry, 14, 3, 178-9.

Tilvis, R. S., Jolkkonen, K. H. P. J. and Strandberg, T. E. 200o. Social networks and dementia. The Lancet, 356, 9223, 77-8. 


\section{Peter Orpin et al.}

Tommis, Y. 2007. Rural-urban differences in the effects on mental well-being of caring for people with stroke or dementia. Aging $\mathcal{E}$ Mental Health, 11, 6, 743-50.

Toseland, R. W., McCallion, P., Gerber, T. and Banks, S. 2002. Predictors of health and human services use by persons with dementia and their family caregivers. Social Science $\mathcal{E}^{2}$ Medicine, 55, 7, $1255^{-66 .}$

United Nations 2010. World Population Prospects: The 2008 Revision. Department of Economic and Social Affairs, Population Division, United Nations, New York.

Wagner, D. L. and Niles-Yokum, K. J. 20o6. Caregiving in a rural context. In Goins, R. T. and Krout, J. A. (eds), Service Delivery to Rural Older Adults: Research Policy and Practice. Springer Publishing Company, New York, $145^{-62 .}$

Wenger, G. C., Scott, A. and Seddon, D. 2002. The experience of caring for older people with dementia in a rural area: using services. Aging $\mathcal{E}^{\circ}$ Mental Health, 6, 1 , $30-8$.

Wimo, A., Sjölund, B. M., Sköldunger, A., Johansson, L., Nordberg, G. and von Strauss, E. 201 1. Incremental patterns in the amount of informal and formal care among non-demented and demented elderly persons results from a 3-year followup population-based study. International Journal of Geriatric Psychiatry, 26, 1, $5^{6-64}$.

Yap, L. K. P., Seow, C. C. D., Henderson, L. M. and Goh, Y. N.J. 20o6. Family caregivers and caregiving in dementia. Reviews in Clinical Gerontology, 15, 3/4, 263-71.

Accepted Iо July 20 I 2; first published online I5 August 2012

Address for correspondence:

Peter Orpin, University Department of Rural Health,

Private Bag 103, Hobart, Tasmania 70oo, Australia.

E-mail: Peter.Orpin@utas.edu.au 